\title{
Annealing of Neutron Damage in Graphite Irradiated and Stored at Room Temperature
}

W. I. Gray

P. A. Thrower

January 1979

Prepared for the U.S. Department of Energy under Contracts EY-76-C-06-1830 and

EV-76-C $-02-2712$

Pacific Northwest Laboratory

Operated for the U.S. Department of Energy

by Battelle Memorial Institute 


\title{
NOTICE
}

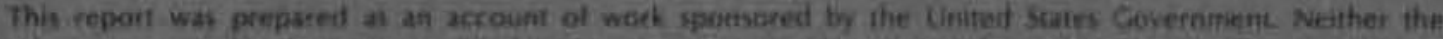

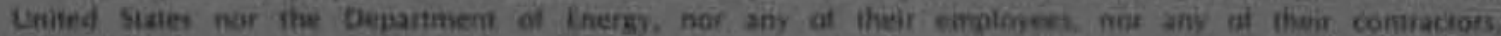

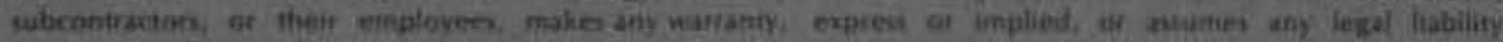

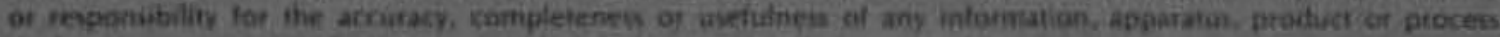

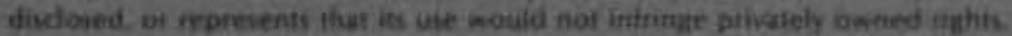

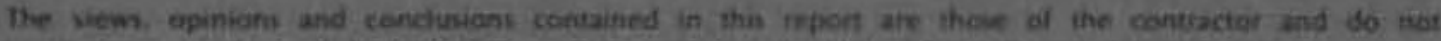

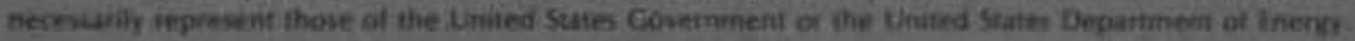

\author{
PACIHC NORTHWEST LABORATORY \\ operaled by \\ вктास⿺ \\ loir the \\ UNITE STATES DEPARTMENT OF INERCI \\ Undec Coneract EY-\%-C.06-1030
}






\section{0}

\section{ANNEALING OF NEUTRON DAMAGE IN GRAPHITE} IRRADIATED AND STORED AT ROOM TEMPERATURE

W. J. Gray (a)
P. A. Thrower (b)

January 1979

Prepared for

the U.S. Department of Energy

under Contracts EY-76-C-06-1830

and $E Y-76-C-02-2712$

Pacific Northwest Laboratory

Richland, Washington 99352

\footnotetext{
(a) Pacific Northwest Laboratory Richland, Washington 99352

(b) Pennsylvania State University University Park, Pennsylvania
} 
The annealing of neutron radiation damage in graphite at the same temperature at which it was irradiated is reported here for the first time. Highly oriented pyrolytic graphite samples were irradiated to fluences in the range 0.44 to $153 \times 10^{15} / \mathrm{cm}^{2}$ at room temperature using three different neutron sources with average energies of $1.5,5.5$. and $15 \mathrm{MeV}$, respectively. Following these irradiations, the $C_{44}$ elastic constants of these samples were measured several times over periods up to two years during which time sample temperatures never exceeded $30^{\circ} \mathrm{C}$. The $\mathrm{C}_{44}$ constants were observed to slowly decrease toward their unirradiated values with up to $40 \%$ of the irradiation-induced changes eventually annealing out. 


\section{TABLE OF CONTENTS}

SUMMARY. . . . . . . . . . . . . . . . . . . . . . .

INTRODUCTION . . . . . . . . . . . . . . . . . . . . . . 1

EXPERIMENTAL . . . . . . . . . . . . . . . . . . . . . 1

RESULTS AND DISCUSSION . . . . . . . . . . . . . . . . . . 2

ACKNOWLEDGEMENTS . . . . . . . . . . . . . . . . . . . . 10

REFERENCES ............................ 11 


\section{INTRODUCTION}

The value of the shear modulus, $\mathrm{C}_{44}$, of Highly Oriented Pyrolytic Graphite (HOPG) has been shown to be sensitive to neutron radiation at very low fluences. (1) we have used this property to determine the relative radiation damage produced by neutrons of different energies. (2) In the process of conducting the latter experiment, the shear modulus was observed to return toward its unirradiated value over periods up to two years. This phenomenon does not appear to have been reported before, and deserves further investigation.

\section{EXPERIMENTAL}

Experimental details have been described elsewhere. (2) Briefly, three grades of HOPG were irradiated to fluences in the range 0.44 to $153 \times 10^{15} / \mathrm{cm}^{2}$ EFF $^{*}$ using the Medical Research Reactor at Brookhaven National Laboratory $(B N L)$, the $(D, B e)$ neutron source at the University of California at Davis, and the Rotating Target Neutron Source at Lawrence Livermore Laboratory (LLL). Neutron energies in these three sourcẻs averaged about 1.5, 5.5, and $15 \mathrm{MeV}$, respectively. Irradiation temperatures in the accelerator target rooms at Davis and LLL were not measured, but were probably about $25^{\circ} \mathrm{C}$ and could not have been above $35^{\circ} \mathrm{C}$; temperatures in the reactor at BNL were measured to be in the range 17 to $23^{\circ} \mathrm{C}$. Sample temperatures during shipment back to PNL following irradiation are unknown and were not necessarily the same for the different sets of samples. About 25 samples were irradiated in each source. The shear modulus, $C_{44}$, of each sample was determined by measuring the velocity, $V$, of a $1 \mathrm{MHz}$ shear wave propagated parallel to the c-axis direction. Reproducibility of the velocity measurements was about $27 \%$. Modulus and sonic velocity are related ${ }^{(3)}$ by

*Fluences used here are in terms of Equivalent Fission Fluence (EFF) for Damage in Graphite(4) using the relative damage function derived by Gray and Morgan (2) rather than the Thompson and Wright function recommended by Ref. 4. 
the expression

$$
E \equiv C_{44}=\Delta V^{2}
$$

where $\rho$ is the graphite density $\left(2260 \mathrm{~kg} / \mathrm{m}^{3}\right)$.

\section{RESULTS AND DISCUSSION}

Tables I to III list moduli at various times after the end of the irradiations. Possible reasons for the observed decrease of the moduli with time include thermal (room temperature) annealing, changes induced by the sonic velocity measurements, and mechanical stresses on the samples during handling.

If thermal annealing is the primary mechanism and one assumes that a single annealing process applies, then the data should fit an equation of the form:

$$
E-E_{\infty}=\left(E_{0}-E_{\infty}\right) e^{-c t}
$$

where $E$ is the modulus at any time, $t$, after irradiation, $E_{\infty}$ is the value of the modulus as $t$ become large, $E_{0}$ is the modulus at the end of irradiation, and $c$ is a constant at any given temperature. Data for individual samples can be fitted, albeit rather crudely in some cases, to such an equation assuming that $E_{\infty}$ is represented by the most recent measurements listed in the last column of Tables I to III. This assumption is justified because the decrease that has occurred between the next-to-last and last measurements is sma 71 . It is insignificant at the $95 \%$ confidence level for the LLL and Davis samples. It appears, therefore, that more time and additional measurements would produce little, if any, further decreases in the measured moduiti.

As an additional test to determine whether the moduli could be further decreased, some samples were annealed at $80^{\circ} \mathrm{C}$. It was feared that higher temperatures would activate additional annealing processes rather than merely assure completion of those processes aiready active at room temperature. Following the measurements at 396 days, two Davis samples were annealed for 22 hours at $80^{\circ} \mathrm{C}$ with essentially no change. Following the 
TABLE 1. Shear Moduli of Samples Irradiated at LLL

\begin{tabular}{|c|c|c|c|c|c|c|c|c|}
\hline No. STI & $\frac{\text { le }}{\text { Type }}$ & $\begin{array}{c}\text { Fluence } \\
\left(10^{15} / \mathrm{cm}^{2}\right)\end{array}$ & $\begin{array}{l}\text { Modul i } \\
21\end{array}$ & $\begin{array}{r}(\mathrm{MPa}) \\
201 \\
\end{array}$ & $\begin{array}{l}\text { vs. No. of } \\
290\end{array}$ & $\begin{array}{c}\text { Days After } \\
502 \\
\end{array}$ & $\begin{array}{c}\text { Irradiat } \\
\quad 704 \\
\end{array}$ & $\begin{array}{l}n^{(3)} \\
734^{(4} \\
\end{array}$ \\
\hline $\begin{array}{r}1 \\
2 \\
3 \\
4 \\
5 \\
11 \\
12 \\
13 \\
14 \\
15 \\
16 \\
17 \\
18 \\
19 \\
20 \\
21 \\
22 \\
23 \\
24 \\
25\end{array}$ & $\begin{array}{l}1 \\
1 \\
1 \\
6 \\
1 \\
1 \\
6 \\
4 \\
1 \\
4 \\
6 \\
4 \\
1 \\
6 \\
4 \\
1 \\
6 \\
4 \\
1 \\
6\end{array}$ & $\begin{array}{l}153 \\
120 \\
92.5 \\
75.4 \\
60.8 \\
36.7 \\
31.6 \\
28.2 \\
24.7 \\
22.2 \\
17.9 \\
13.7 \\
12.6 \\
11.5 \\
7.26 \\
6.78 \\
6.32 \\
2.16 \\
2.06 \\
1.95\end{array}$ & $\begin{array}{r}2008 \\
1714 \\
1535 \\
1064 \\
1164 \\
828 \\
680 \\
667 \\
728 \\
558 \\
559 \\
439 \\
526 \\
443 \\
354 \\
394 \\
396 \\
284 \\
311 \\
317\end{array}$ & $\begin{array}{r}1735 \\
1624 \\
1449 \\
937 \\
1023 \\
748 \\
624 \\
579 \\
649 \\
501 \\
508 \\
416 \\
476 \\
416 \\
335 \\
377 \\
386 \\
278 \\
304 \\
324\end{array}$ & $\begin{array}{r}1738 \\
1621 \\
1383 \\
972 \\
983 \\
728 \\
609 \\
592 \\
619 \\
493 \\
515 \\
411 \\
464 \\
423 \\
333 \\
372 \\
366 \\
283 \\
302 \\
329\end{array}$ & $\begin{array}{r}1540 \\
1510 \\
1284 \\
916 \\
915 \\
657 \\
568 \\
536 \\
577 \\
465 \\
493 \\
389 \\
433 \\
405 \\
322 \\
353 \\
358 \\
272 \\
297 \\
299\end{array}$ & $\begin{array}{r}1463 \\
1439 \\
1239 \\
879 \\
891 \\
643 \\
550 \\
516 \\
549 \\
453 \\
473 \\
371 \\
405 \\
385 \\
308 \\
349 \\
336 \\
266 \\
280 \\
310\end{array}$ & $\begin{array}{r}1480 \\
1223 \\
1035 \\
850 \\
867 \\
657 \\
532 \\
522 \\
547 \\
452 \\
446 \\
357 \\
400 \\
399 \\
304 \\
340 \\
345 \\
270 \\
287 \\
296\end{array}$ \\
\hline $\begin{array}{r}6 S \\
7 S \\
8 S \\
9 S \\
10 S\end{array}$ & $\begin{array}{l}1 \\
1 \\
6 \\
6 \\
4\end{array}$ & 47.1 & $\begin{array}{l}901 \\
981 \\
841 \\
805 \\
809\end{array}$ & $\begin{array}{l}829 \\
869 \\
783 \\
749 \\
712\end{array}$ & $\begin{array}{l}796 \\
749 \\
730\end{array}$ & $\begin{array}{l}728 \\
699 \\
665\end{array}$ & $\begin{array}{l}722 \\
662 \\
651\end{array}$ & $\begin{array}{l}617 \\
609 \\
655\end{array}$ \\
\hline
\end{tabular}

(1) Sample numbers followed by "S" were oriented with their basal planes parallel to the neutron beam; all others were perpendicular to the beam.

(2) Refers to width, in degrees, of the (002) x-ray diffraction peak at half-maximum intensity.

(3) Before irradiation, moduli were 264, 249, and $304 \mathrm{MPa}$ for sample types 1, 4, and 6 respectively.

(4) Moduli following $80^{\circ} \mathrm{C}$ anneal for 260 hours. 
TABLE II. Shear Moduli of Samples Irradiated At Davis

\begin{tabular}{|c|c|c|c|c|c|c|c|c|c|}
\hline \multirow{2}{*}{\multicolumn{2}{|c|}{$\frac{\text { Sample }}{\text { No.(1) Type }}(2)$}} & Fluence & \multicolumn{2}{|c|}{ Moduli (MPa } & \multirow{2}{*}{\multicolumn{5}{|c|}{ vs. No. of Days after Irradiation (3) }} \\
\hline & & $\left(10^{15} / \mathrm{cm}^{2}\right)$ & 6 & 13 & 19 & & & & 396 \\
\hline 2 & 1 & 85.6 & 1501 & 1363 & 1143 & 1105 & 1051 & 1092 & 1098 \\
\hline 3 & 1 & 68.4 & 1367 & 1091 & 1150 & 1048 & 1083 & 1086 & 945 \\
\hline 4 & 1 & 42.7 & 930 & 845 & 829 & 755 & 736 & 756 & 680 \\
\hline 5 & 4 & 37.5 & 779 & 751 & 695 & 658 & 622 & 646 & 624 \\
\hline 6 & 1 & 33.8 & 825 & 717 & 712 & 687 & 670 & & 657 \\
\hline 7 & 6 & 30.5 & 666 & 631 & 601 & 581 & 565 & & 552 \\
\hline 8 & 4 & 28.0 & 647 & 606 & 598 & 551 & 541 & & 510 \\
\hline 9 & 1 & 24.9 & 677 & 625 & 586 & 587 & 551 & & 554 \\
\hline 10 & 6 & 22.5 & 573 & 542 & 535 & 536 & 492 & & 472 \\
\hline 11 & 4 & 20.7 & 536 & 513 & 496 & 468 & 449 & & 449 \\
\hline 12 & 1 & 7.94 & 428 & 406 & 371 & 362 & 349 & & 346 \\
\hline 13 & 6 & 7.42 & 388 & 391 & 391 & 371 & 354 & & 360 \\
\hline 14 & 4 & 7.00 & 349 & 353 & 332 & 341 & 314 & & 315 \\
\hline 15 & 1 & 2.20 & 307 & 305 & 300 & 297 & 287 & & 290 \\
\hline 16 & 6 & 2.13 & 337 & 333 & 329 & 330 & 323 & & 328 \\
\hline 17 & 4 & 2.05 & 278 & 274 & 280 & 278 & 271 & & 265 \\
\hline 18 & 1 & 0.474 & 281 & 278 & 276 & 272 & 265 & & 271 \\
\hline 19 & 6 & $0.15 i$ & 310 & 308 & 308 & 313 & 304 & & 310 \\
\hline 20 & 4 & 0.443 & 265 & 260 & 262 & 261 & 251 & & 277 \\
\hline 15 & 67 & & 953 & 865 & 856 & 873 & 821 & & 761 \\
\hline 25 & $\exists$ & & 1071 & 1082 & 969 & 1012 & 887 & & 837 \\
\hline $3 S$ & 1 & 51.3 & & 812 & 824 & 734 & 753 & & \\
\hline 45 & 6 & & & 828 & 745 & 767 & 724 & & 723 \\
\hline $5 S$ & 6 & & 753 & 726 & 688 & 704 & 673 & & 677 \\
\hline
\end{tabular}

(1) Sample numbers followed by "S" were oriented with their basal planes parallel to the neutron beam; all others were perpendicular to the beam.

(2) Refers to widths, in degrees, of the (002) x-ray diffraction peak at half-maximum intensity.

(3) Before irradiation, moduli were 264, 249, and $304 \mathrm{MPa}$ for sample types 1, 4, and 6 respectively. 
TABLE III. Shear Moduli of Samples Irradiated at BNL

\begin{tabular}{ccc} 
Fluence & Moduli (MPa) vs. No. of Days After Irradiation (2) \\
Sample & $\begin{array}{c}14,15(3) \\
\text { 1ro. Type }\end{array}(1)\left(1015 / \mathrm{cm}^{2}\right)$ \\
\hline
\end{tabular}

Capsule \#1

$\begin{array}{ll}1 & 1 \\ 2 & 1 \\ 3 & 1 \\ 4 & 4 \\ 5 & 4 \\ 6 & 4 \\ 7 & 6 \\ 8 & 6 \\ 9 & 6\end{array}$

$85.2 \quad 1292$
1306
1115
1111
1073
1087
1018
986
1002

$\begin{array}{rrrr}1240 & 1191 & 1064 & 1101 \\ 1188 & & 1149 & 1120 \\ 1221 & 1174 & 1110 & 1052 \\ 1095 & 1078 & 1012 & 1023 \\ 1071 & 1036 & 993 & 983 \\ 1008 & 983 & 942 & 905 \\ 989 & & 955 & 946 \\ 956 & 956 & 912 & 909 \\ 908 & 911 & 904 & 907\end{array}$

1113
1152
1079
1005
975
950
946
906
898

$\begin{array}{rr}1120 & 991 \\ 1107 & 1068 \\ 994 & 940 \\ 959 & 929 \\ 943 & 933 \\ 883 & 883 \\ 908 & 891 \\ 902 & 888 \\ 872 & 848\end{array}$

Capsule \#2

\begin{tabular}{|l}
$36.6 \quad 800$ \\
.739 \\
781 \\
706 \\
649 \\
606 \\
662 \\
687 \\
706
\end{tabular}

$\begin{array}{llll}770 & & 762 & 678 \\ 627 & 650 & 666 & 647 \\ 803 & & 725 & 683 \\ 686 & .677 & 666 & 627 \\ 625 & & 641 & 610 \\ 639 & & 647 & 628 \\ 663 & & 664 & 655 \\ 663 & 635 & 632 & 637 \\ 668 & & 647 & 647\end{array}$

711
606
687
642
613
641
647
619
640

$\begin{array}{ll}667 & 675 \\ 610 & 610 \\ 682 & 660 \\ 613 & 603 \\ 612 & 609 \\ 616 & 598 \\ 639 & 618 \\ 608 & 622 \\ 584 & 609\end{array}$

Capsule \#3

$\begin{array}{ll}1 & 1 \\ 2 & 1 \\ 3 & 1 \\ 4 & 4 \\ 5 & 4 \\ 6 & 4 \\ 7 & 6 \\ 8 & 6 \\ 9 & 6\end{array}$

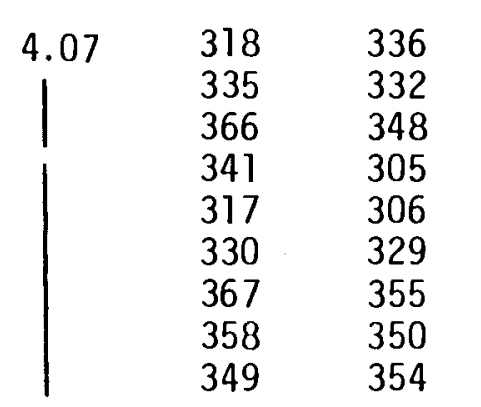

$\begin{array}{ll}324 & 323 \\ 317 & 323 \\ 333 & 320 \\ 299 & 291 \\ 304 & 298 \\ 309 & 307 \\ 347 & 332 \\ 345 & 352 \\ 352 & 344\end{array}$

$\begin{array}{lll}322 & 325 & 302 \\ 331 & 325 & 317 \\ 329 & 322 & 330 \\ 294 & 288 & 293 \\ 300 & 299 & 304 \\ 312 & 316 & 308 \\ 347 & 353 & 346 \\ 354 & 349 & 346 \\ 358 & 358 & 359\end{array}$

(1) Refers to width, in degrees, of the (002) x-ray diffraction peak at half-maximum intensity.

(2) Before irradiation, moduli were 264 and $304 \mathrm{MPa}$ for sample tvpes 1 and 6 respectively; for - 3 sample type 4 they were $249 \mathrm{MPa}$ for capsule \#l and $261 \mathrm{MPa}$ for capsules \#2 and \#3.

- (3) First number applies to rapsules \#? and \#3, second nimber anplies to capsule \#1. 
measurements at 194 days, all of the $6^{\circ}$ samples from the first BNL capsule were annealed for 113 hours at $80^{\circ} \mathrm{C}$ with essentially no change. Annealing data for LLL samples are shown in Table I. By discounting samples 2 and 3 which appear to be in error, the average change due to annealing at $80^{\circ} \mathrm{C}$ is insignificant at the $95 \%$ confidence level.

A somewhat improved fit to equation 2 was made by normalizing the data for each sample to the change at infinite time, and averaging the norma 1 ized values. In other words, equation 2 was normalized by dividing by $E_{\infty}-E_{u}$ where $E_{u}$ refers to the modulus of the unirradiated sample. Thus, the quantity $\left(E-E_{\infty}\right) /\left(E_{\infty}-E_{u}\right)$ was calculated at each time for each sample. At low fluences, where $E_{\infty}$ was only slightly larger than $E_{u}$, large uncertainties exist. Also, there may be some tendency for $\left(E-E_{\infty}\right) /\left(E_{\infty}-E_{u}\right)$ to be larger at lower fluences. Therefore, samples with fluences lower than $8 \times 10^{15} / \mathrm{cm}^{2}$ EFF were not included in the average. Results are shown in Fig. 1. The BNL data fit quite we 17 , and a reasonable fit occurs for the LLL data. The fit for the Davis data is not as good as for the other two sets. In fact, two straight lines, one for short times and the second for longer times, would produce a much better fit. Such behavior could be explained by two different annealing mechanisms with different time constants but this is considered unlikely because the mean neutron energy at the Davis facility was mid-way between those at the BNL and LLL facilities.

Instead of, or in addition to, thermal annealing it seemed possible that the measurements themselves might somehow be causing the moduli to decrease. A few LLL and Davis samples were measured two or three times on a given day with essentialiy the same resuits each time. Oniy the BNL samples were systematically checked to determine if the sonic velocity measurements had any effect. The data are shown in Table III. Most of the measurements on a given day are within experimental error of one another. Nevertheless, the second measurement usualiy gave the lower value and, although the average of the second measurements was only slightly lower, the difference is statistically significant. Thus, there is some indication that a change occurred during the measurements. 


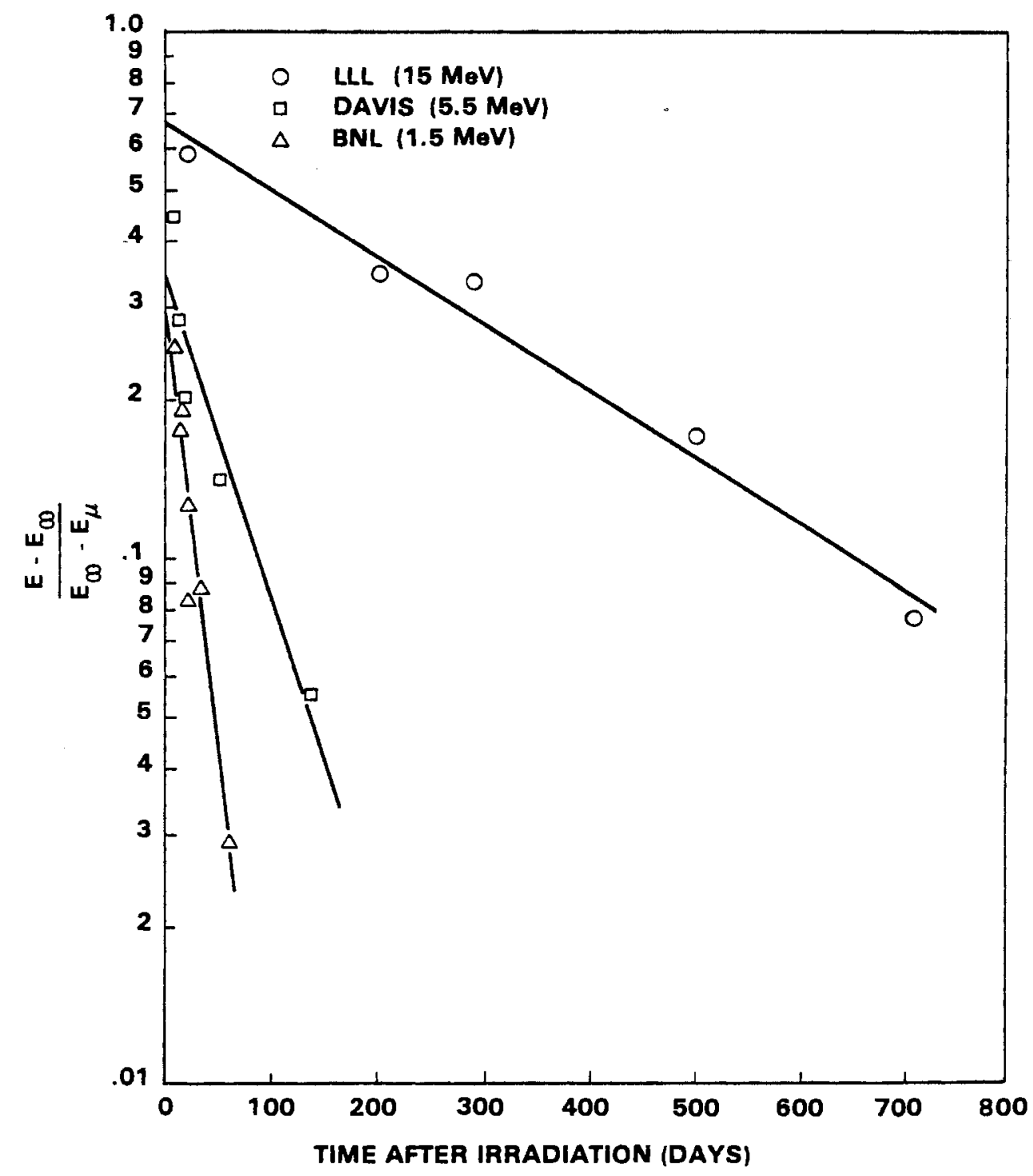

Figure 1. Change of Shear Modulus with Time. 
A few samples were allowed to stand for periods up to 3 hours with the sonic waves continuously passing through them, and the measured moduli were almost exactly the same at the beginning and end of these periods. During normal measurements, waves passed through the samples for only about 5 minutes. Thus, it would appear that the energy from the sonic pulses has not caused the modulus to change.

Mechanical stress induced during handling included pressing the transducers against opposite sides of the samples together with a slight back-and-forth twisting motion to remove excess coupling agent and to make sure that a maximum signal strength was achieved (this torsional mechanical stress was sufficient to cleave about eight samples during the hundreds of measurements). Stresses of this magnitude, even when the sample was not cleaved, might have been enough to cause defect migration. To the extent that the mechanical energy supplied during preparation for a measurement was approximately the same each time, the jecrease should be exponential with the number of measurements. Fig. 2 shows the same data as Fig. 1 , replotted as a function of the number of measurements. The data fit a straight line relationship about equally well in both figures.

Other trends shown by the data presented in Table I to III and Figs. 1 and 2 are as follows:

- For samples irradiated in a given facility, no difference in annealing behavior was found between the three grades of graphite or between samples oriented differently relative to the neutron beam axis.

- The time constant, $c$, from equation 2 is much lower for the LLL samples than for the other two sample sets.

- The amount of annealing that occurred since the samples were first measured was less for the BNL samples even though they were measured more times.

There is no question that the shear moduli of all samples have decreased since the first time they were measured after irradiation, but 


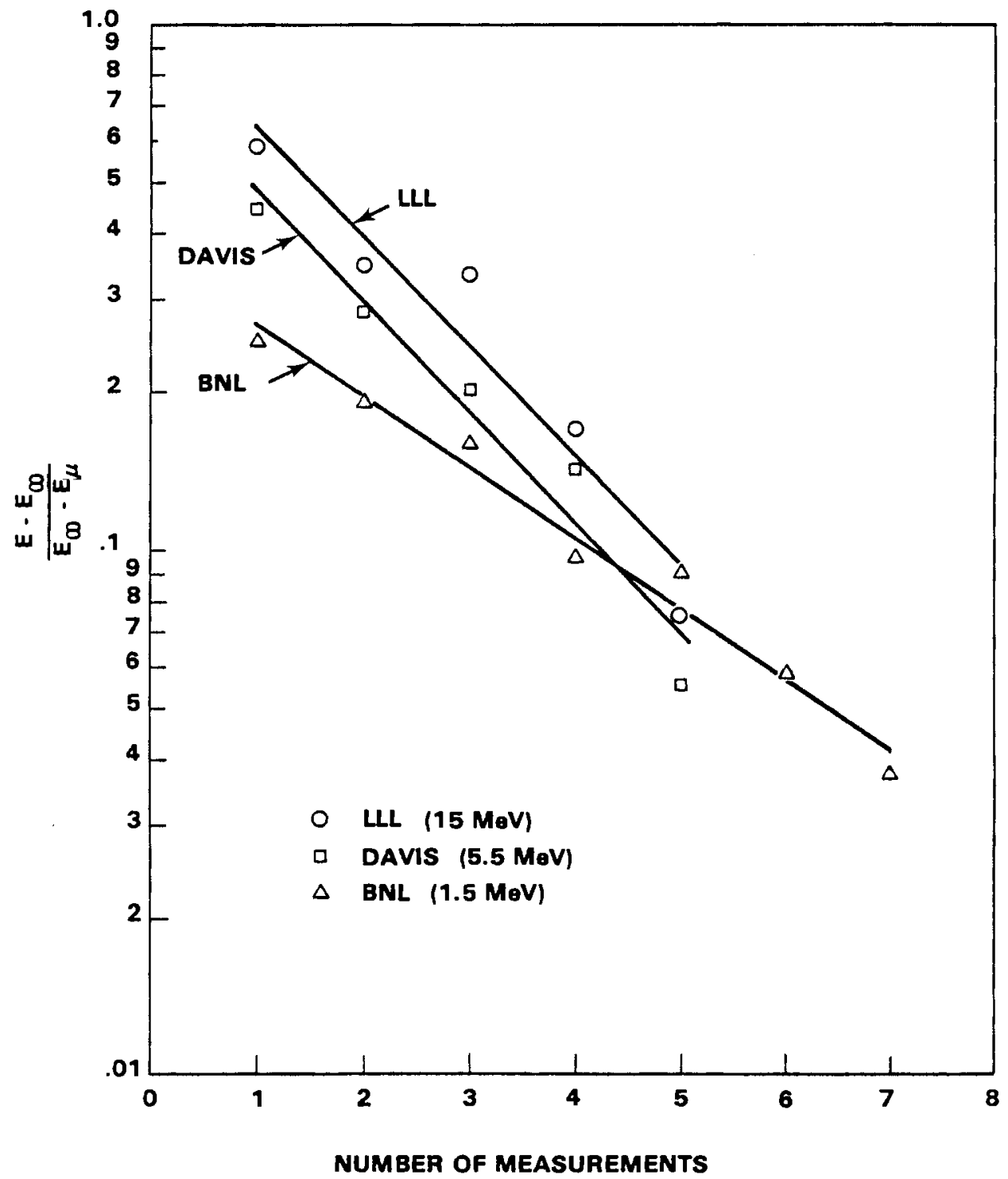

Figure 2. Change of Shear Modulus with Number of Measurements. 
the cause or causes have not been firmly established. He believe that at least part of the change was due to thermal annealing. However, the case for an effect due to the measurements and/or associated handling is nearly as strong. Apparently the sonic pulses cause no change, but stresses imposed on the samples during handling may do so.

Attempts were made to observe changes with time in the defect distribution using high resolution electron microscopy. BNL samples were examined within 48 hours of their removal from the reactor and at regular intervals during the following year. Each time, the defects were observed to be small interstitial clusters $\leqslant 1.5 \mathrm{~nm}$ in diameter. No differences in their character or distribution were observed. This finding is not necessarjly in disagreement with the modulus measurements, however, because the defects were barely resolvable and the changes with time might have been too subtle to resolve.

\section{ACKNOWLEDGEMENTS}

The authors would like to thank $F$. D. Hobbs for his many arduous hours spent preparing samples and performing modulus measurements. Thanks are also due W. C. Morgan for useful discussions and help in data analysis. 


\section{REFERENCES}

1. R. E. Taylor and D. E. Kline, "Effects of Reactor Irradiation on the Dynamic Mechanical Behavior of Graphites and Carbons," Chemistry and Physics of Carbon, Vol. 6 p. 283, P. L. Walker, Jr. (ed), Marcel Dekker, Inc., N.Y., 1970.

2. W. J. Gray and W. C. Morgan, "Damage Function for Carbon at Neutron Energies up to $15 \mathrm{MeV}$," paper presented at the First Topical Meeting on Fusion Reactor Materials, Miami Beach, Florida, Jan. 29-31, 1979.

3. A. E. H. Love, A Treatise on the Mathematical Theory of Elasticity, Fourth Edition, Dover Publications, N.Y. 1944.

4. "Standard Recommended Practice for Reporting Dosimetry Results on Nuclear Graphite," ASTM Designation E525, Annual Book of ASTM Standards, Part 45. 


\section{DISTRIBUTION}

No. of

Copies

OFFSITE

1 DOE Chicago Patent Group 9800 South Cass Avenue Argonne, IL 60439

A. A. Churm

3 DOE Office of Fusion Energy

K. M. Zwilsky

M. M. Cohen

T. C. Reuther

27 DOE Technical Information Center

2 Oak Ridge National Laboratory P. 0. Box X Oak Ridge, TN 37830

J. L. Scott

H. P. Eatherly

G. B. Engle General Atomic Company

P. 0. Box 81608

San Diego, CA 92138

6 P. A. Thrower

Materials Science Department

Pennsylvania State University

University Park, PA 16802

D. G. Fischbach

University of Washington

Seattle, WA 92105
No. of

Copies

ONSITE

1 DOE Richland Operations Office Programs Division

H. E. Ransom

Pacific Northwest Laboratory

T. D. Chikalla

D. A. Dingee

15 W. J. Gray

R. P. Marshall

W. C. Morgan

R. E. Nightingale

G. L. Tingey

E. M. Woodruff

5 Technical Information Files

- 2 Publishing Coordination 
